\title{
(C) OPEN ACCESS \\ Career specialty choices of UK medical graduates of 2015 compared with earlier cohorts: questionnaire surveys
}

\author{
Trevor William Lambert, Fay Smith, Michael J Goldacre
}

\begin{abstract}
- Additional material is published online only. To view please visit the journal online (http://dx.doi.org/10.1136/ postgradmedj-2017-135309).
\end{abstract}

UK Medical Careers Research Group, Unit of Health-Care Epidemiology, Nuffield Department of Population Health, University of Oxford, Oxford, UK

\section{Correspondence to} Trevor William Lambert, UK Medical Careers Research Group, Unit of Health-Care Epidemiology, Nuffield Department of Population Health, University of Oxford, Oxford OX3 7LF, UK: trevor.lambert@dph.ox.ac.uk

Received 6 September 2017 Revised 5 January 2018 Accepted 27 January 2018 Published Online First 12 February 2018
Check for updates

To cite: Lambert TW, Smith F Goldacre MJ. Postgrad Med J 2018;94:191-197

\begin{abstract}
Objective To report the career specialty choices of UK medical graduates of 2015 one year after graduation and to compare these with the choices made at the same postgraduate stage by previous cohorts.

Design National survey using online and postal questionnaires.

Setting UK.

Participants UK-trained medical graduates.

Main outcome measures Grouped and individual specialty choices.

Results The response rate was 41.3\% (3040/7095).
\end{abstract}

Among the graduates of 2015 , general practice $(27.8 \%$ of first choices) and hospital medical specialties (26.5\%) were the most frequent first choices of long-term career. First choices for general practice declined among women from $36.1 \%$ for the $2005-2009$ cohorts to $33.3 \%$ for the 2015 cohort, and among men from $22.4 \%$ for the 2005-2009 cohorts to $19.3 \%$ for the 2015 cohort. First choices for surgery declined among men (from $29.5 \%$ for the $2005-2009$ cohorts to $21.7 \%$ for the 2015 cohort), but not among women $(12.3 \%$ for the 2005-2009 cohorts and 12.5\% for the 2015 cohort). There was an increase in the percentage of first choices for anaesthesia, psychiatry, radiology and careers outside medicine. Anaesthesia, oncology, paediatrics and radiology increased in popularity over time among men, but not among women.

Conclusions Career choices for general practice remain low. Other current shortage specialties, apart from radiology and psychiatry, are not showing an increase in the number of doctors who choose them. Large gender differences remain in the choices for some specialties. Further work is needed into the determinants of junior doctors' choices for shortage specialties and those with large gender imbalances.

\section{INTRODUCTION}

Currently there are a number of specialties in UK medicine with known shortages of doctors and difficulties in filling available training posts. A February 2016 report by NHS Improvement, the body charged with 'helping the NHS to meet its short-term challenges and secure its future', identified emergency medicine, acute general medicine, diagnostic services (radiology and pathology) and psychiatry as being particularly under challenge. ${ }^{1}$ The NHS Improvement report focused on hospital services and did not specifically address general practice. A recent systematic review confirmed the challenges to recruitment in primary care, and found that early exposure to primary care practice was an important consideration in motivating recruitment. $^{2}$

Information on career choices of newly qualified doctors is important for long-term planning. Early choices are highly correlated with specialty destinations. Our previous studies of the long-term career plans of UK medical graduates surveyed 1 year after graduation have included the cohorts of 1974 , 1977, 1980, 1983, 1993, 1996, 1999, 2000 and 2002 in order to provide this information. ${ }^{3-6}$ Here we add data from five cohorts of UK medical graduates between 2005 and 2015. The aim of this paper was to report the career choices of the graduates of 2015 one year after graduation and to compare these with the choices made by previous cohorts at the same career stage, to present trends in firmness of specialty choice, to compare men's and women's choices, and to compare career choices of graduates from different UK medical schools.

\section{METHODS}

The UK Medical Careers Research Group surveyed the UK medical graduates of 2015. We sent questionnaires 1 year after qualification (in JuneOctober 2016) to all medical graduates of 2015 from all UK medical schools. Up to four reminders were sent to non-respondents. Further details of the methodology are available elsewhere. ${ }^{7}$ We draw comparisons with our surveys, also at 1 year after qualification, of the 2005, 2008, 2009 and 2012 cohorts who were surveyed using similar methods.

We asked respondents What is your choice of longterm career specialty? inviting them to nominate up to three choices in order of preference and to indicate if any of the choices were of equal preference ('tied' choices). Doctors described their specialty choices in their own words, and we assigned each response to a specialty, and if necessary a subspecialty, according to a coding scheme developed over many years and based on nationally recognised designation of specialties. Individual specialties were grouped by us into 14 groupings. We then asked How sure are you about the first choice given above? with definite, probable and unsure being the possible responses. For this paper, we counted the number of doctors who chose each specialty as a first choice (whether tied or untied).

In the analysis we constructed a binary variable for certainty of choice by combining those who replied definite or probable versus those who 
Table 1 First choice of long-term career of UK medical graduates of 2015, surveyed in 2016: broad specialty groupings, comparing men and women

\begin{tabular}{|c|c|c|c|c|c|c|c|c|}
\hline \multirow[b]{2}{*}{ Grouped specialty } & \multicolumn{3}{|l|}{ Numbers } & \multicolumn{3}{|c|}{ Percentages } & \multicolumn{2}{|c|}{ Men-women comparison } \\
\hline & $\begin{array}{l}\text { Total } \\
(\mathrm{N}=3040)\end{array}$ & $\begin{array}{l}\text { Men } \\
(\mathrm{N}=1206)\end{array}$ & Women $(\mathrm{N}=1834)$ & Total & Men & Women & $\chi^{2}$ value & $P$ value $(d f=1)$ \\
\hline General practice & 844 & 233 & 611 & 27.8 & 19.3 & 33.3 & 79.4 & $<0.001$ \\
\hline Hospital medical specialties & 805 & 294 & 511 & 26.5 & 24.4 & 27.9 & 4.4 & 0.037 \\
\hline Surgery & 492 & 262 & 230 & 16.2 & 21.7 & 12.5 & 44.6 & $<0.001$ \\
\hline Anaesthesia & 480 & 251 & 229 & 15.8 & 20.8 & 12.5 & 37.3 & $<0.001$ \\
\hline Paediatrics & 261 & 82 & 179 & 8.6 & 6.8 & 9.8 & 7.8 & 0.005 \\
\hline Emergency medicine & 171 & 80 & 91 & 5.6 & 6.6 & 5.0 & 3.5 & 0.061 \\
\hline Psychiatry & 165 & 66 & 99 & 5.4 & 5.5 & 5.4 & 0.0 & 0.994 \\
\hline Obstetrics and gynaecology & 164 & 26 & 138 & 5.4 & 2.2 & 7.5 & 40.0 & $<0.001$ \\
\hline Pathology & 97 & 42 & 55 & 3.2 & 3.5 & 3.0 & 0.4 & 0.524 \\
\hline Radiology & 92 & 53 & 39 & 3.0 & 4.4 & 2.1 & 12.0 & $<0.001$ \\
\hline Radiotherapy and oncology & 78 & 36 & 42 & 2.6 & 3.0 & 2.3 & 1.1 & 0.285 \\
\hline Public health & 28 & 9 & 19 & 0.9 & 0.7 & 1.0 & 0.4 & 0.533 \\
\hline Community health & 9 & 1 & 8 & 0.3 & 0.1 & 0.4 & 2.0 & 0.158 \\
\hline Other medical specialties & 21 & 7 & 14 & 0.7 & 0.6 & 0.8 & 0.1 & 0.710 \\
\hline Not stated & 105 & 31 & 74 & 3.5 & 2.6 & 4.0 & 4.3 & 0.039 \\
\hline Non-medical & 44 & 23 & 21 & 1.4 & 1.9 & 1.1 & 2.5 & 0.117 \\
\hline
\end{tabular}

Note: The numbers given are for tied and untied first choices.

replied unsure to the question How sure are you about the first choice given above?

We used non-parametric tests $\left(\chi^{2}\right.$ tests, Mantel-Haenszel $\chi^{2}$ tests for linear trend) to compare patterns of choices between subgroups and to explore trends. When there were significant differences, we used adjusted standardised residuals to identify unusually high or low cell counts for individual specialties or grouped specialties.

\section{RESULTS}

\section{Response rate}

In 2015, 7364 UK doctors graduated (3240 men, 4124 women). We obtained contact details for 7095 of them (96.3\%). Of these, 3040 responded, hence the response rate was 41.3\% (3040/7095) (men 38.8\% (1206/3109), women 46.0\% (1834/3986)). The 269 members of the cohort who we could not contact included 43 who declined to participate and 226 for whom no contact details could be found. For comparison, the response rates for the surveys of the graduates of 2012, 2009, 2008 and 2005 reported here were, respectively, 45.9\%, 46.7\%, 49.0\% and $61.0 \%$.

\section{First choice of long-term career: graduates of 2015}

The most popular first choice of long-term career was general practice $(27.8 \%$ of doctors gave it as their untied or tied first choices; table 1). Specialties that we group as the medical specialties accounted for $26.5 \%$ of first choices; these are medical specialties, mainly practised in hospital, comprising those described by the doctors as cardiology, chest medicine, clinical pharmacology, dermatology, endocrinology, gastroenterology, general (internal) medicine, genitourinary medicine, geriatrics, infectious diseases, nephrology, neurology, occupational medicine, rheumatology/rehabilitation and tropical medicine. Two other grouped specialties were selected by over $10 \%$ of respondents: the surgical specialties (16.2\%) and anaesthesia (15.8\%).

A higher percentage of women than men chose general practice (33.3\% compared with 19.3\%) and obstetrics and gynaecology $(7.5 \%$ compared with $2.2 \%)$. A higher percentage of men than women chose surgery, anaesthesia and radiology (men: $21.7 \%, 20.8 \%$ and $4.4 \%$, respectively; women: $12.5 \%, 12.5 \%$ and $2.1 \%)$.

\section{Firmness of career intentions: comparing the cohorts}

The graduates of 2015 and 2012 were marginally more confident about their career choices than their predecessors; $80.8 \%$ of doctors from the 2015 cohort and $83.0 \%$ from the 2012 cohort described their choice as definite or probable compared with $77.3 \%$ from the 2005-2009 cohorts $\left(\chi_{1}^{2}=24.8, \mathrm{P}<0.001\right.$ linear trend; table 2). In the 2015 and 2012 cohorts, those who chose either radiology or surgery were most confident about their choice (table 2). Women graduates from 2015 were less certain about their career choices than men $\left(\chi_{1}^{2}=14.8, \mathrm{P}<0.001\right)$; $77.3 \%$ of women described their choice as definite or probable compared with $83.1 \%$ of men. The gender difference was not significant in the other cohorts.

More doctors who chose surgery described their choice as a definite or probable choice in more recent cohorts than in earlier cohorts: $86.3 \%$ of doctors from the 2015 cohort compared with $80.0 \%$ of doctors from the $2005-2009$ cohorts $\left(\chi_{1}^{2}=11.9\right.$, $\mathrm{P}<0.001)$. Doctors in more recent cohorts who chose hospital medical specialties were surer of their choice than were their predecessors; $67.3 \%$ of doctors from the 2015 cohort who chose hospital medical specialties regarded their choice as definite or probable compared with $60.6 \%$ from the $2005-2009$ cohorts $\left(\chi_{1}^{2}=15.6, \mathrm{P}<0.001\right)$. Doctors who chose other grouped specialties did not show significant trends across the cohorts in their firmness of career intentions (table 2).

\section{Comparison with earlier graduation years}

Table 3 shows, in emboldened lines, equivalent data on the choices by grouped specialty of the cohort of 2012 and the combined cohorts of 2005, 2008 and 2009.

Comparing the level of choices for each grouped specialty, anaesthesia, psychiatry and radiology showed appreciable upward trends in popularity, while general practice and surgery showed modest declines. Choices for other specialty groupings 
Table 2 Percentage (and number, $\mathrm{n}$ ) who described their choice as a definite or probable choice, for doctors who chose each specialty group ( $\mathrm{N}$ ): UK medical graduates surveyed 1 year after graduation

\begin{tabular}{|c|c|c|c|c|c|c|c|c|}
\hline \multirow[b]{3}{*}{ Grouped specialty* } & \multicolumn{8}{|c|}{ Cohort group } \\
\hline & \multicolumn{2}{|l|}{2015} & \multicolumn{2}{|l|}{2012} & \multicolumn{2}{|c|}{ 2005, 2008 and 2009} & \multicolumn{2}{|c|}{ Linear trend } \\
\hline & $\%$ & $\mathrm{n} / \mathrm{N}$ & $\%$ & $\mathrm{n} / \mathrm{N}$ & $\%$ & $n / N$ & $\chi^{2}$ value & $P$ value $(d f=1)$ \\
\hline Radiology & 86.8 & $79 / 91$ & 82.5 & $47 / 57$ & 73.2 & $131 / 179$ & 7.1 & 0.008 \\
\hline Surgery & 86.3 & $421 / 488$ & 85.3 & $301 / 353$ & 80.0 & $1253 / 1566$ & 11.9 & $<0.001$ \\
\hline Psychiatry & 78.7 & $129 / 164$ & 73.9 & $68 / 92$ & 78.0 & $256 / 328$ & 0.0 & 0.981 \\
\hline Community health & 77.8 & $7 / 9$ & 33.3 & $2 / 6$ & 44.4 & $4 / 9$ & NA & NA \\
\hline General practice & 76.1 & $638 / 838$ & 80.4 & $555 / 690$ & 75.9 & $2016 / 2656$ & 0.6 & 0.457 \\
\hline Obstetrics and gynaecology & 75.0 & $123 / 164$ & 82.3 & $102 / 124$ & 70.7 & $352 / 498$ & 2.6 & 0.108 \\
\hline Anaesthesia & 73.6 & $349 / 474$ & 80.4 & $242 / 301$ & 72.5 & $766 / 1057$ & 0.9 & 0.356 \\
\hline Radiotherapy and oncology & 73.1 & $57 / 78$ & 74.1 & $43 / 58$ & 68.7 & $125 / 182$ & 0.7 & 0.415 \\
\hline Paediatrics & 72.8 & $190 / 261$ & 80.3 & $171 / 213$ & 74.9 & $586 / 782$ & 0.1 & 0.798 \\
\hline Non-medical & 71.4 & $30 / 42$ & 43.8 & $7 / 16$ & 49.2 & $31 / 63$ & 4.6 & 0.031 \\
\hline Emergency medicine & 69.0 & $118 / 171$ & 77.7 & $80 / 103$ & 61.6 & $252 / 409$ & 4.6 & 0.031 \\
\hline Public health & 67.9 & $19 / 28$ & 55.2 & $16 / 29$ & 61.4 & $51 / 83$ & 0.1 & 0.699 \\
\hline Hospital medical specialties & 67.3 & $533 / 792$ & 68.9 & $430 / 624$ & 60.6 & $1360 / 2244$ & 15.6 & $<0.001$ \\
\hline Other medical specialties & 66.7 & $14 / 21$ & 83.3 & $10 / 12$ & 56.9 & $41 / 72$ & 1.3 & 0.257 \\
\hline Pathology & 66.0 & $64 / 97$ & 76.1 & $51 / 67$ & 67.3 & $152 / 226$ & 0.0 & 0.968 \\
\hline All respondents* & 80.8 & $2343 / 2900$ & 83.0 & $1831 / 2206$ & 77.3 & $6387 / 8263$ & 24.8 & $<0.001$ \\
\hline
\end{tabular}

Note: Due to low numbers, $\chi^{2}$ could not be calculated for community health.

* Excludes respondents who did not state a specialty choice or the level of certainty of their career choice. NA, not applicable.

did not show any trend. Statistical test results are shown in table 3 footnotes.

The recent rise in the percentage of respondents who did not nominate a career choice is noteworthy. It increased from $0.2 \%$ (combined 2005, 2008 and 2009 cohorts) to 3.8\% of respondents from the 2012 cohort and $3.5 \%$ of respondents from the 2015 cohort. This pattern was observed for both men and women. A higher percentage of 2015 graduates chose non-medical careers (table 3).

Some grouped specialty trends differed for men and women. There was a decline in first choices for surgery among men (29.5\% for the 2005-2009 cohorts to $21.7 \%$ for the 2015 cohort; $\left.\chi_{1}^{2}=30.5, \mathrm{P}<0.001\right)$, but not among women $(12.3 \%$ to $\left.12.5 \% ; \chi_{1}^{2}<0.1, \mathrm{P}=0.876\right)$. There was a decline in first choices for general practice among women $(36.1 \%$ for the 2005-2009 cohorts to $33.3 \%$ for the 2015 cohort; $\left.\chi_{1}^{2}=6.0, \mathrm{P}<0.05\right)$, but not significantly so among men $\left(22.4 \%\right.$ to $19.3 \% ; \chi_{1}^{2}=3.4$, $\mathrm{P}=0.066)$.

There was a rise in the percentage of first choices for paediatrics among men (4.6\% for the 2005-2009 cohorts to $6.8 \%$ for the 2015 cohort; $\left.\chi_{1}^{2}=8.2, \mathrm{P}<0.01\right)$ and a decline among women $\left(11.7 \%\right.$ to $\left.9.8 \% ; \chi_{1}^{2}=4.6, \mathrm{P}<0.05\right)$. There was a rise in the percentage of first choices for anaesthesia among men (15.1\% for the 2005-2009 cohorts to $20.8 \%$ for the 2015 cohort; $\left.\chi_{1}^{2}=17.1, \mathrm{P}<0.001\right)$, but not among women $(11.0 \%$ to $\left.12.5 \% ; \chi_{1}^{2}=3.5, \mathrm{P}=0.61\right)$. There was a rise in first choices for oncology among men (1.5\% for the 2005-2009 cohorts to $3.0 \%$ for the 2015 cohort; $\left.\chi_{1}^{2}=10.6, \mathrm{P}<0.001\right)$, but not among women $\left(2.5 \%\right.$ to $\left.2.3 \% ; \chi_{1}^{2}=0.1, \mathrm{P}=0.710\right)$. There was a rise in first choices for radiology among men (2.9\% for the 2005-2009 cohorts to $4.4 \%$ for the 2015 cohort; $\left.\chi_{1}^{2}=6.6, \mathrm{P}<0.01\right)$, but not among women $\left(1.7 \%\right.$ to $\left.2.1 \% ; \chi_{1}^{2}=1.2, \mathrm{P}=0.268\right)$. There was a rise in first choices for non-medical specialties among men (1.0\% for the 2005-2009 cohorts to $1.9 \%$ for the 2015 cohort; $\left.\chi_{2}^{2}=5.8, \mathrm{P}<0.05\right)$, but not among women $(0.7 \%$ to $1.1 \%$; $\left.\chi_{1}^{2}=3.5, \mathrm{P}=0.063\right)$.

\section{First choice of career specialty: detailed career choices}

As well as the grouped specialty choices, table 3 also shows the numbers and percentages of first choices for each individual career specialty.

We show the details for interested readers, without further comment on most specialties. Within hospital medical specialties, most choices were for general medicine. Similarly, within surgical specialties large numbers of graduates designated general surgery as their first choice 1 year after graduation. Many numbers for individual specialties were small counts; it was, however, noteworthy that there was an increase across the cohorts in the percentage of first choices that were for geriatrics, a decline in choices for cardiology and an increase for ophthalmology.

Online supplementary appendix 1 shows separately for men and women the percentages who chose each individual specialty as a first choice of career. We do not offer detailed analysis of the gender differences, recognising that many of the percentages are based on even smaller counts than those of table 3 and analysis would lack statistical power. But as for table 3, we tabulate the results for the interested reader. We draw attention to the male preponderance of choices for cardiology, nephrology and neurology, and the female preponderance in choices for geriatrics and for dermatology.

\section{Grouped specialty career choice and clinical medical school attended: graduates of $\mathbf{2 0 1 5}$}

Table 4 shows, for graduates of 2015, the numbers and percentages of first choices for each grouped specialty subdivided by the location of the clinical medical school attended. For general practice and surgery, we found significant differences by medical school in the level of choices. We have combined all other grouped specialties in table 4, as there were no significant differences for any individual specialty; online supplementary appendix 2 gives a detailed breakdown. 
Table 3 Numbers and percentages of doctors who gave each specialty as their first choice of long-term career: UK medical graduates of 2015, 2012, 2009, 2008 and 2005 surveyed 1 year after graduation: detailed specialty breakdown

\begin{tabular}{|c|c|c|c|c|c|c|}
\hline \multirow[b]{2}{*}{ Grouped/individual specialty } & \multicolumn{3}{|c|}{ Graduation year (Numbers) } & \multicolumn{3}{|c|}{ Graduation year (\%) } \\
\hline & $\begin{array}{l}2005,2008 \text { and } \\
2009(N=8537)\end{array}$ & $2012(\mathrm{~N}=2313)$ & $2015(\mathrm{~N}=3040)$ & $\begin{array}{l}2005,2008 \text { and } \\
2009(\mathrm{~N}=8537)\end{array}$ & $2012(\mathrm{~N}=2313)$ & $2015(\mathrm{~N}=3040)$ \\
\hline General practice & 2669 & 694 & 844 & 31.3 & 30.0 & 27.8 \\
\hline Cardiology & 285 & 77 & 71 & 3.3 & 3.3 & 2.3 \\
\hline Chest medicine & 188 & 45 & 52 & 2.2 & 1.9 & 1.7 \\
\hline Endocrinology & 75 & 15 & 23 & 0.9 & 0.6 & 0.8 \\
\hline Gastroenterology & 184 & 52 & 56 & 2.2 & 2.2 & 1.8 \\
\hline General medicine & 747 & 165 & 257 & 8.8 & 7.1 & 8.5 \\
\hline Genitourinary medicine & 46 & 24 & 26 & 0.5 & 1.0 & 0.9 \\
\hline Geriatrics & 134 & 73 & 94 & 1.6 & 3.2 & 3.1 \\
\hline Infectious diseases & 112 & 29 & 39 & 1.3 & 1.3 & 1.3 \\
\hline Rheumatology/Rehabilitation & 77 & 29 & 33 & 0.9 & 1.3 & 1.1 \\
\hline Tropical medicine & 26 & 7 & 6 & 0.3 & 0.3 & 0.2 \\
\hline Surgery & 1573 & 358 & 492 & 18.4 & 15.5 & 16.2 \\
\hline Cardiac surgery & 19 & 8 & 18 & 0.2 & 0.3 & 0.6 \\
\hline Ear, nose and throat & 117 & 35 & 47 & 1.4 & 1.5 & 1.5 \\
\hline General surgery & 517 & 75 & 167 & 6.1 & 3.2 & 5.5 \\
\hline Neurosurgery & 86 & 21 & 23 & 1.0 & 0.9 & 0.8 \\
\hline Ophthalmology & 138 & 38 & 71 & 1.6 & 1.6 & 2.3 \\
\hline Oral and maxillofacial surgery & 45 & 12 & 16 & 0.5 & 0.5 & 0.5 \\
\hline Trauma and orthopaedic surgery & 323 & 76 & 95 & 3.8 & 3.3 & 3.1 \\
\hline Paediatric surgery & 55 & 16 & 14 & 0.6 & 0.7 & 0.5 \\
\hline Psychiatry & 331 & 95 & 165 & 3.9 & 4.1 & 5.4 \\
\hline Child/adolescent psychiatry & 33 & 4 & 3 & 0.4 & 0.2 & 0.1 \\
\hline Forensic psychiatry & 17 & 6 & 1 & 0.2 & 0.3 & $<0.1$ \\
\hline General psychiatry & 272 & 84 & 160 & 3.2 & 3.6 & 5.3 \\
\hline Learning disabilities & 2 & 0 & 0 & $<0.1$ & 0.0 & 0.0 \\
\hline Psychogeriatrics & 10 & 0 & 0 & 0.1 & 0.0 & 0.0 \\
\hline Psychotherapy & 5 & 2 & 0 & 0.1 & 0.1 & 0.0 \\
\hline Obstetrics and gynaecology & 501 & 127 & 164 & 5.9 & 5.5 & 5.4 \\
\hline Pathology & 228 & 67 & 97 & 2.7 & 2.9 & 3.2 \\
\hline Forensic medicine & 16 & 0 & 5 & 0.2 & 0.0 & 0.2 \\
\hline General pathology & 22 & 4 & 8 & 0.3 & 0.2 & 0.3 \\
\hline Genetics & 25 & 10 & 9 & 0.3 & 0.4 & 0.3 \\
\hline Haematology & 101 & 35 & 46 & 1.2 & 1.5 & 1.5 \\
\hline Histopathology & 27 & 7 & 12 & 0.3 & 0.3 & 0.4 \\
\hline Immunology & 7 & 3 & 7 & 0.1 & 0.1 & 0.2 \\
\hline Microbiology & 36 & 8 & 12 & 0.4 & 0.3 & 0.4 \\
\hline Radiology & 180 & 57 & 92 & 2.1 & 2.5 & 3.0 \\
\hline Radiotherapy and oncology & 182 & 58 & 78 & 2.1 & 2.5 & 2.6 \\
\hline Public health & 83 & 29 & 28 & 1.0 & 1.3 & 0.9 \\
\hline Community health & 10 & 6 & 9 & 0.1 & 0.3 & 0.3 \\
\hline Family planning & 8 & 6 & 8 & 0.1 & 0.3 & 0.3 \\
\hline
\end{tabular}


Table 3 Continued

\begin{tabular}{|c|c|c|c|c|c|c|}
\hline \multirow[b]{2}{*}{ Grouped/individual specialty } & \multicolumn{3}{|c|}{ Graduation year (Numbers) } & \multicolumn{3}{|c|}{ Graduation year (\%) } \\
\hline & $\begin{array}{l}2005,2008 \text { and } \\
2009(N=8537)\end{array}$ & $2012(\mathrm{~N}=2313)$ & $2015(N=3040)$ & $\begin{array}{l}2005,2008 \text { and } \\
2009(N=8537)\end{array}$ & $2012(\mathrm{~N}=2313)$ & $2015(\mathrm{~N}=3040)$ \\
\hline General Community health & 2 & 0 & 1 & $<0.1$ & 0.0 & $<0.1$ \\
\hline Other medical specialties & 72 & 13 & 21 & 0.8 & 0.6 & 0.7 \\
\hline Not stated & 18 & 88 & 105 & 0.2 & 3.8 & 3.5 \\
\hline Non-medical & 65 & 16 & 44 & 0.8 & 0.7 & 1.4 \\
\hline
\end{tabular}

Notes: The grouped specialty total in bold may be lower than the total of each individual specialty belonging to that group: if a respondent gave 'Anaesthetics' as their tied first choice with 'Intensive care/anaesthesia', this would only result in one count at the grouped specialty level.

Linear trend statistics across the cohorts: general practice $\left(\chi_{1}^{2}=12.9, \mathrm{P}<0.001\right)$, hospital medical specialties $\left(\chi_{1}^{2}=0.0, \mathrm{P}=0.961\right)$, surgery $\left(\chi_{1}^{2}=11.0, \mathrm{P}<0.001\right)$, anaesthesia $\left(\chi^{2}=19.9\right.$,

$\mathrm{P}<0.001)$, paediatrics $\left(\chi_{1}^{2}=0.8, \mathrm{P}=0.367\right)$, emergency medicine $\left(\chi_{1}^{2}=2.3, \mathrm{P}=0.129\right)$, psychiatry $\left(\chi_{1}^{2}=12.0, \mathrm{P}<0.001\right)$, obstetrics and gynaecology $\left(\chi_{1}^{2}=1.1\right.$, $\left.\mathrm{P}=0.295\right)$, pathology $\left(\chi_{1}^{2}=2.3\right.$,

$\mathrm{P}=0.133)$, radiology $\left(\chi^{2}=8.2, \mathrm{P}=0.004\right)$, radiotherapy and oncology $\left(\chi^{2}=2.3, \mathrm{P}=0.132\right)$, public health $\left(\chi_{1}^{2}=0.0, \mathrm{P}=0.967\right)$, community health $\left(\chi^{2}=4.7\right.$, $\left.\mathrm{P}=0.030\right)$, other medical specialties

$\left(\chi_{1}^{2}=1.2, \mathrm{P}=0.283\right)$, not stated $\left(\chi_{1}^{2}=206.7, \mathrm{P}<0.001\right)$ and non-medical $\left(\chi_{1}^{2}=9.7, \mathrm{P}=0.002\right)$.

Graduates from the medical schools in London and Oxbridge medical schools (ie, Oxford and Cambridge schools, combined) were less likely than others to choose general practice; graduates from Wales and 'Rest of England' were more likely to do so $\left(\chi_{5}^{2}=52.4, \mathrm{P}<0.001\right)$. This difference was more pronounced among women $\left(\chi_{5}^{2}=34.3, \mathrm{P}<0.001\right)$; among men the difference was only marginally significant $\left(\chi_{5}^{2}=13.6, \mathrm{P}=0.018\right)$.

Female graduates from London medical schools were more likely to choose surgery than women from other medical schools $\left(\chi_{5}^{2}=26.1, \mathrm{P}<0.001\right)$; this difference was not observed among men $(\mathrm{P}=0.810)$.

\section{DISCUSSION}

\section{Main findings}

In the qualification cohort of 2015, 1 year after graduation, just over a quarter of first choices were for general practice and a quarter for the hospital medical specialties. Proportionately more women than men chose general practice and obstetrics and gynaecology, and more men than women chose surgery, anaesthesia and radiology.

Comparing the level of choices for each grouped specialty, anaesthesia, psychiatry, radiology and non-medical careers showed an upward trend in popularity, while general practice and surgery showed a downward trend. The rise in the number of doctors replying 'don't know' and being unable to specify a career choice is noteworthy and may be related to recent contractual uncertainties about future jobs, as discussed below.

Paediatrics rose in popularity among men but declined among women. Anaesthesia, oncology, radiology and 'non-medical' all rose in popularity among men, but showed no change among women. There was a decrease in interest recently, among women, for general practice, and no evidence of an increase in interest among men. Interest in surgery has also declined recently among men.

Most specialty choices within the hospital medical specialties were for general medicine, and within surgery were for general surgery. There was an increase in interest in geriatric medicine among recent graduates. Choices for general practice were highest among graduates from Wales and English medical schools outside London and Oxbridge.

Recent graduates were more certain about their career choices than their predecessors. Doctors choosing radiology and surgery were more certain of their choice than doctors choosing other specialties.

Care must be taken in interpretation of results from a single cohort, although we do have results from previous cohorts for comparison. Decisions about career choice may be affected by the doctors' perceptions of many factors, personal and environmental. Personal factors include self-reflection and taking a view about the specialty to which one is essentially suited, as well as practical considerations such as the nature of the work and working conditions, perceived work-life balance, and future personal or financial prospects. External factors include

Table 4 Clinical medical school attended and first choice of longterm career (\%): UK medical graduates of 2015, surveyed in 2016

\begin{tabular}{|c|c|c|c|}
\hline \multirow[b]{2}{*}{$\begin{array}{l}\text { Clinical medical } \\
\text { school attended }\end{array}$} & \multicolumn{3}{|c|}{ First choice of career (row percentages) } \\
\hline & General practice & Surgery & $\begin{array}{l}\text { All others } \\
\text { combined }\end{array}$ \\
\hline Men & $\mathrm{P}=0.018$ & $\mathrm{P}=0.810$ & $\mathrm{P}=0.118$ \\
\hline Oxbridge ( $\mathrm{N}=95)$ & 9.5 & 22.1 & 76.8 \\
\hline London $(\mathrm{N}=304)$ & 16.8 & 22.0 & 66.4 \\
\hline $\begin{array}{l}\text { Rest of } \\
\text { England }(\mathrm{N}=606)\end{array}$ & 21.6 & 21.5 & 69.5 \\
\hline Scotland $(N=121)$ & 16.5 & 24.0 & 66.9 \\
\hline Wales $(\mathrm{N}=47)$ & 29.8 & 23.4 & 55.3 \\
\hline $\begin{array}{l}\text { Northern } \\
\text { Ireland (N=33) }\end{array}$ & 24.2 & 12.1 & 66.7 \\
\hline Total $(\mathrm{N}=1206)$ & 19.3 & 21.7 & 68.4 \\
\hline Women & $P<0.001$ & $P<0.001$ & $\mathrm{P}=0.329$ \\
\hline Oxbridge ( $\mathrm{N}=92)$ & 21.7 & 12.0 & 73.9 \\
\hline London $(\mathrm{N}=370)$ & 24.9 & 19.2 & 67.8 \\
\hline $\begin{array}{l}\text { Rest of } \\
\text { England (N=984) }\end{array}$ & 37.9 & 10.5 & 64.9 \\
\hline Scotland $(N=229)$ & 28.4 & 13.5 & 67.7 \\
\hline Wales $(\mathrm{N}=107)$ & 43.0 & 4.7 & 68.2 \\
\hline $\begin{array}{l}\text { Northern } \\
\text { Ireland (N=52) }\end{array}$ & 28.8 & 17.3 & 61.5 \\
\hline Total $(\mathrm{N}=1834)$ & 33.3 & 12.5 & 66.4 \\
\hline All & $P<0.001$ & $\mathrm{P}=0.007$ & $\mathrm{P}=0.067$ \\
\hline Oxbridge $(\mathrm{N}=187)$ & 15.5 & 17.1 & 75.4 \\
\hline London $(\mathrm{N}=674)$ & 21.2 & 20.5 & 67.2 \\
\hline $\begin{array}{l}\text { Rest of } \\
\text { England (N=1590) }\end{array}$ & 31.7 & 14.7 & 66.7 \\
\hline Scotland $(\mathrm{N}=350)$ & 24.3 & 17.1 & 67.4 \\
\hline Wales $(\mathrm{N}=154)$ & 39.0 & 10.4 & 64.3 \\
\hline $\begin{array}{l}\text { Northern } \\
\text { Ireland (N=85) }\end{array}$ & 27.1 & 15.3 & 63.5 \\
\hline Total $(\mathrm{N}=3040)$ & 27.8 & 16.2 & 67.2 \\
\hline
\end{tabular}

Notes: The percentages given are for tied and untied first choices. The table excludes 105 'not stated' responses. Row percentages add to more than $100 \%$ because doctors were allowed to specify up to three first choices of equal preference. See online supplementary appendix 2 for breakdown of results for the 'All others combined' column. Percentages whose adjusted residuals are greater than \pm 2.58 are shown in bold. 
knowledge about the demand for doctors in different specialties, the opportunities for training and the eventual career prospects.

Our results offer only limited encouragement in respect of supply to the shortage specialties mentioned in the Introduction section, namely general practice, emergency medicine, general medicine, radiology, pathology and psychiatry. We report modest rises in the level of choices for radiology, pathology and psychiatry, although general medicine and emergency medicine choices remained largely static and general practice choices appear, if anything, to have declined, despite well-publicised national initiatives to increase recruitment and the creation of additional training places.

For many years now, the percentage of newly qualified doctors who want a career in general practice has been well below the $50 \%$ deemed necessary to meet service needs. ${ }^{8}$ Our surveys suggest that too few junior doctors leave medical school enthused sufficiently about a career in general practice to want to pursue it. As we have noted elsewhere, ${ }^{9}$ this should not be taken to imply that careers in general practice are unattractive, but that careers in other branches of medicine are more attractive. We noted in $2006^{3}$ that there was 'no evidence that there has been any increase in interest recently in general practice as a career among newly qualified doctors' and that conclusion remains justified. We have also questioned whether medical schools should have strategies for training preferentially for careers in particular branches of medical practice, notably for careers in general practice. ${ }^{10}$ We commented then that we thought this would not be preferred by either medical students or by medical schools, but given the seemingly intractable issue of a shortfall of doctors wanting careers in general practice, we suggest now that it might be worth considering.

\section{Strengths and limitations}

This study investigated the career choices of a large number of doctors from across the UK over a 10 -year period. The strengths of our study include its ongoing data collection covering many years, its large size, its inclusion of all UK medical schools and its independence. We surveyed the doctors at a key decision-making time in terms of choosing their future careers: between June and October 2016 for the graduates of 2015. We note that a response rate of $41 \%$ is somewhat low and is lower than in our previous year 1 surveys. Reduced survey research participation in recent years has been reported elsewhere among health professionals and other populations. ${ }^{11}{ }^{12}$ However, our own studies have obtained high response rates from older doctors in recent years. ${ }^{13}$ For example, a recent survey by us of mainly retired doctors in the UK obtained a response rate of $85 \%$. We suspect, therefore, that there is a generational factor in play in non-response to surveys. ${ }^{14}$

\section{Comparison with existing literature and future work}

The declining trend in first choices for general practice between the cohorts of 1993 and 2002 which we found in a previous study has continued in the current study (between the cohorts of 2005 and 2015). ${ }^{3}$ Other research has found that general practice has declined in attractiveness relative to hospital practice. ${ }^{9}$ The decrease in interest in general practice we observed was more evident among women than men. This decline among women is in line with other research, which has found that while female general practitioners in particular value a career that offers 'compatibility with family life', many doctors are leaving general practice due to high workload and too much administration. ${ }^{15-18}$ In particular, the trans-European study by Roos and colleagues ${ }^{17}$ showed many similarities between the views of UK trainees and recent qualifiers in general practice and their counterparts in other European countries. The USA is also experiencing difficulties in sustaining sufficient medical graduate interest in general practice to meet national needs. ${ }^{19}$

We observed in the 2015 cohort a rise in the number of doctors unable to specify a career specialty choice. Junior doctors based in England have reported elsewhere that contractual uncertainty has made them switch specialty choice or made them uncertain about switching specialty. ${ }^{20}$

To date, in addition to papers covering a range of specialties within individual cohorts, ${ }^{3-6}$ we have written in detail on career choices for individual specialties including general practice, emergency medicine, geriatric medicine, cardiology, surgery, psychiatry, public health, the hospital medical specialties, trauma and orthopaedic surgery, ophthalmology, paediatrics, radiology, obstetrics and gynaecology, pathology, and anaesthesia. ${ }^{8} 21-33$ The survey reported here is the last that our group will undertake, as the Department of Health, the funding body, will shortly cease funding the work. It is therefore unlikely that there will be future data on the career intentions, nationally, of junior UK-trained doctors soon after graduating from medical school. Other organisations, like the British Medical Association and individual medical schools, should be encouraged to undertake future studies of newly qualified doctors' career intentions.

\section{IMPLICATIONS/CONCLUSIONS}

There is no evidence in these surveys of an increase in the number of first-year postgraduate doctors who express a career choice for general practice. Further work might include focus groups of junior doctors to explore in-depth views on the perceived strengths and weaknesses of the administrative and clinical features of working in general practice in the UK, and whether there is anything distinctive to be learnt from Welsh medical schools, which had the highest levels of choices for general practice in the UK in this study. Focus groups would need to be large enough to ensure that representative views were captured.

Similarly, our results do not offer comfort with regard to supply issues in other current shortage specialties in the UK, with the possible exceptions of radiology and psychiatry, which show modest evidence of increase in interest; similar further work might address the underlying issues.

\section{Main messages}

- Career choices for general practice remain low and comprised a third of women and a fifth of men in this cohort.

- Other shortage specialties-emergency medicine, general medicine, radiology, pathology and psychiatry - do not show evidence of growth in popularity.

- Large gender differences remain in choices for careers in surgery and anaesthesia.

\section{Current research questions}

- Why have initiatives to increase gender balance in certain specialties been unsuccessful to date?

- Can focus groups offer insight into junior doctors' perceptions of careers in general practice?

- What factors are driving the increase in the number of doctors unable to make a career choice? 
Large gender differences in career choices remain, particularly in choices for general practice, surgery and anaesthesia. Further research could seek to identify why the various initiatives designed to increase gender balance have to date been unsuccessful.

Acknowledgements We thank Ritva Ellison for data management, and Janet Justice and Alison Stockford for data entry. We are very grateful to all the doctors who participated in the surveys.

Contributors TWL and MJG designed and conducted the surveys. FS performed the analysis and wrote the first draft of the paper. All authors contributed to further drafts and all approved the final version.

Funding This is an independent report commissioned and funded by the Policy Research Programme of the Department of Health (project number 016/0118). The views expressed are not necessarily those of the funding body.

Competing interests None declared.

Ethics approval National Research Ethics Service, following referral to the Brighton and Mid-Sussex Research Ethics Committee in its role as a multicentre research ethics committee (ref 04/Q1907/48 amendment Am02 March 2015).

Provenance and peer review Not commissioned; externally peer reviewed.

Data sharing statement It may be possible for the authors to make tabulated data, produced in the course of this work but not included in the paper, available to interested readers on request.

Open Access This is an Open Access article distributed in accordance with the Creative Commons Attribution Non Commercial (CC BY-NC 4.0) license, which permits others to distribute, remix, adapt, build upon this work non-commercially, and license their derivative works on different terms, provided the original work is properly cited and the use is non-commercial. See: http://creativecommons.org/ licenses/by-nc/4.0/

(c) Article author(s) (or their employer(s) unless otherwise stated in the text of the article) 2018. All rights reserved. No commercial use is permitted unless otherwise expressly granted.

\section{REFERENCES}

1 NHS Improvement. Evidence from NHS Improvement on clinical staff shortages: A workforce analysis. London: NHS Improvement, 2016.

2 Marchand C, Peckham S. Addressing the crisis of GP recruitment and retention: a systematic review. Br J Gen Pract 2017;67:e227-37.

3 Lambert TW, Goldacre MJ, Turner G. Career choices of United Kingdom medical graduates of 2002: questionnaire survey. Med Educ 2006;40:514-21.

4 Lambert TW, Goldacre MJ, Turner G. Career choices of United Kingdom medical graduates of 1999 and 2000: questionnaire surveys. BMJ 2003;326:194-5.

5 Goldacre MJ, Davidson JM, Lambert TW. Career choices at the end of the preregistration year of doctors who qualified in the united kingdom in 1996. Med Educ 1999;33:882-9.

6 Lambert TW, Goldacre MJ, Edwards C, et al. Career preferences of doctors who qualified in the United Kingdom in 1993 compared with those of doctors qualifying in 1974, 1977, 1980, and 1983. BMJ 1996;313:19-24.

7 Goldacre MJ, Lambert TW. Participation in medicine by graduates of medical schools in the United Kingdom up to 25 years post graduation: national cohort surveys. Acad Med 2013;88:699-709.

8 Lambert T, Goldacre M. Trends in doctors' early career choices for general practice in the UK: longitudinal questionnaire surveys. Br J Gen Pract 2011;61:397-403.

9 Lambert TW, Smith F, Goldacre MJ. Trends in attractiveness of general practice as a career: surveys of views of UK-trained doctors. Br J Gen Pract 2017;67:e238-47.
10 Goldacre MJ, Turner G, Lambert TW. Variation by medical school in career choices of UK graduates of 1999 and 2000. Med Educ 2004;38:249-58.

11 Cook JV, Dickinson HO, Eccles MP. Response rates in postal surveys of healthcare professionals between 1996 and 2005: an observational study. BMC Health Serv Res 2009;9:160

12 The Electoral Commission. Great Britain's electoral registers. London: The Electora Commission, 2011.

13 Smith F, Lachish S, Goldacre MJ, et al. Factors influencing the decisions of senior UK doctors to retire or remain in medicine: national surveys of the UK-trained medical graduates of 1974 and 1977. BMJ Open 2017:7:7:e017650.

14 Svirko E, Goldacre MJ, Lambert T. Career choices of the United Kingdom medical graduates of 2005, 2008 and 2009: questionnaire surveys. Med Teach 2013:35:365-75

15 Sansom A, Calitri R, Carter M, et al. Understanding quit decisions in primary care: a qualitative study of older GPs. BMJ Open 2016;6:e010592.

16 Doran N, Fox F, Rodham K, et al. Lost to the NHS: a mixed methods study of why GPs leave practice early in England. Br J Gen Pract 2016;66:e128-34.

17 Roos $M$, Watson J, Wensing M, et al. Motivation for career choice and job satisfaction of GP trainees and newly qualified GPs across Europe: a seven countries crosssectional survey. Educ Prim Care 2014;25:202-10.

18 NHS. Securing the future GP workforce-delivering the mandate on GP expansion: GP Taskforce final report. England: NHS, 2014.

19 Kozakowski SM, Travis A, Marcinek JP, et al. Entry of Medical School Graduates Into Family Medicine Residencies: 2016-2017. Fam Med 2017;49:686-92.

20 Spooner S, Gibson J, Rigby D, et al. Stick or twist? Career decision-making during contractual uncertainty for NHS junior doctors. BMJ Open 2017;7:e013756.

21 Svirko E, Lambert T, Brand L, et al. Career choices for emergency medicine: national surveys of graduates of 1993-2009 from all UK medical schools. Emerg Med J 2014;31:556-61.

22 Maisonneuve JJ, Pulford C, Lambert TW, et al. Career choices for geriatric medicine: national surveys of graduates of 1974-2009 from all UK medical schools. Age Ageing 2014:43:535-41.

23 Smith F, Lambert TW, Pitcher A, et al. Career choices for cardiology: cohort studies of UK medical graduates. BMC Med Educ 2013:13:10.

24 Goldacre MJ, Laxton L, Lambert TW, et al. Career choices for public health: cohort studies of graduates from UK medical schools. J Public Health 2011;33:616-23.

25 Lambert TW, Goldacre MJ, Bron AJ. Career choices for ophthalmology made by newly qualified doctors in the United Kingdom, 1974-2005. BMC Ophthalmol 2008;8:8.

26 Goldacre MJ, Willett K, Lambert TW. Career choices for trauma and orthopaedic surgery: 30 years of surveys. The Bulletin of the Royal College of Surgeons of England 2008:90:134-8.

27 Turner G, Lambert TW, Goldacre MJ, et al. Career choices for paediatrics: national surveys of graduates of 1974-2002 from UK medical schools. Child Care Health Dev 2007:33:340-6.

28 Turner G, Lambert TW, Goldacre MJ, et al. Career choices for obstetrics and gynaecology: national surveys of graduates of 1974-2002 from UK medical schools. BJOG 2006;113:350-6.

29 Turner G, Lambert TW, Goldacre MJ. Career choices for radiology: national surveys of graduates of 1974-2002 from UK medical schools. Clin Radiol 2006:61:1047-54.

30 Lambert TW, Goldacre MJ, Turner G, et al. Career choices for pathology: national surveys of graduates of 1974-2002 from UK medical schools. J Pathol 2006;208:446-52.

31 Turner G, Goldacre MJ, Lambert T, et al. Career choices for anaesthesia: national surveys of graduates of 1974-2002 from UK medical schools. Br J Anaesth 2005:95:332-8.

32 Goldacre MJ, Turner G, Fazel S, et al. Career choices for psychiatry: national surveys of graduates of 1974-2000 from UK medical schools. Br J Psychiatry 2005;186:158-64.

33 Goldacre MJ, Lambert TW, Laxton L. Career choices made for the hospital medical specialties by graduates from UK medical schools, 1974-2005. Clin Med 2009:9:42-8. 